\title{
DA (IM)PRESCRITIBILIDADE DA PRETENSÃO DE REPARAÇÃO CIVIL DE DANOS PATRIMONIAIS REFLEXOS DOS DANOS AMBIENTAIS
}

\author{
Antonieta Caetano Gonçalves* \\ Ricardo Tadeu Dias Andrade** \\ Thiago de Miranda Carneiro ${ }^{* * *}$
}

\begin{abstract}
Resumo
O presente artigo buscará defender a imprescritibilidade da pretensão reparatória dos danos patrimoniais reflexos dos ambientais, considerando o Recurso Extraordinário n. 654833/AC, 2020, com repercussão geral, em que o Supremo Tribunal Federal reconheceu a imprescritibilidade da pretensão reparatória de dano ambiental. Para tanto, utilizar-se-á o método indutivo de análise de decisões do referido tribunal e do Superior Tribunal de Justiça, o método hermenêutico teleológico e sistemático e a técnica da ponderação de princípios da teoria discursiva do Direito. Concluir-se-á que se deve reconhecer a imprescritibilidade, em razão, principalmente, de os danos patrimoniais reflexos dos ambientais serem uma extensão dos últimos.

Palavras-chave: Meio ambiente ecologicamente equilibrado. Segurança jurídica. Danos ambientais. Danos patrimoniais reflexos. Imprescritibilidade.

\section{THE (IM)PRESCRIPTIBILITY OF CLAIM TO CIVIL REPAIR OF PROPERTY DAMAGES RESULTING FROM ENVIRONMENTAL DAMAGES}

\begin{abstract}
This article aims to defend the imprescriptibility of claim to civil repair for property damages resulting from environmental damages, considering Extraordinary Appeal n. 654833/AC, 2020, with general repercussion, in which Federal Supreme Court recognized the imprescriptibility of reparation claim for environmental damages. Inductive method of analysis of aforementioned court decisions and Superior Court of Justice, teleological and systematic hermeneutic method and technique of principles balancing in Discursive Theory of Law will be used. It will be concluded that imprescriptibility must be recognized, mainly due

\footnotetext{
"Doutoranda em Meio Ambiente pela Escola Superior Dom Helder Câmara. Mestra em Instituições Sociais, Direito e Democracia. Graduação em Direito pela Pontifícia Universidade Católica de Minas Gerais (2014). Graduação em Ciências Contábeis pelo Centro Universitário Newton Paiva (1989). Currículo Lattes: http://lattes.cnpq.br/1317347950255642. Endereço postal: Rua Alvarenga Peixoto, $\mathrm{n}^{\circ}$ 745, apto 1601, Lourdes - Belo Horizonte/MG, CEP 30.280-120. E-mail: acmarins@bol.com.br. ORCID: http://orcid.org/0000-000156239318.

*** Doutorando em Meio Ambiente pela Escola Superior Dom Helder Câmara. Mestre em Instituições Sociais, Direito e Democracia pela Universidade Fumec. Mestre em Direito das Relações Econômicas e Sociais pela Faculdade Milton Campos. Pós-graduado em Direito Público e em Direito Notarial. Procurador da Fazenda Nacional. Currículo Lattes: http://lattes.cnpq.br/8238300958113706. Endereço postal: Avenida Afonso Pena, 3924, apto 805, Cruzeiro - Belo Horizonte/MG, CEP 30.130-009. E-mail: ricardotda @ hotmail.com. ORCID: http://orcid.org/0000-0002-7652-5706.

"** Doutorando em Sustentabilidade e Direito Ambiental pela Escola Superior Dom Helder Câmara. Mestre em Sustentabilidade e Direito Ambiental pela Escola Superior Dom Helder Câmara. Mestre em Direito Privado pela Universidade FUMEC. Currículo Lattes: http://lattes.cnpq.br/0826770658348020. Endereço postal: Rua thiagodemirandacarneiro@yahoo.com.br. ORCID: http://orcid.org/0000-0001-7218-3078.
} da Mata, $\mathrm{n}^{\circ}$ 85, apto 1304, Vila da Serra - Nova lima/MG, CEP 34.006-086. E-mail:
\end{abstract}


to the fact that property damages resulting from environmental damages are an extension of the latter.

Keywords: Ecologically balanced environment. Legal security. Environmental damages. Reflex property damages. Imprescriptibility.

\section{INTRODUÇÃO}

O Supremo Tribunal Federal dirimiu a controvérsia sobre a prescritibilidade da pretensão de reparação por dano ambiental, no Recurso Extraordinário n. 654833/AC, no Tema 999 com repercussão geral, assentando, por maioria de votos, a imprescritibilidade. Contudo, em voto divergente, o ministro Luís Roberto Barroso levantou a questão de ser necessária, a análise de um caso concreto para a afirmação incontroversa da imprescritibilidade dessa pretensão também para danos individuais, que envolvam reflexos patrimoniais do dano ambiental provocado.

Isso porque o mérito do referido recurso envolveu uma ação coletiva, tendo como protagonistas jurídicos a Fundação Nacional do Índio (FUNAI) e o Ministério Público Federal, por ter afetado, não apenas pela via mediata toda a coletividade, mas também, pela via imediata, todo um povo indígena, qual seja, a comunidade Ashaninka-Kampa do Rio Amônia, situada no Acre. Os direitos de domínio sobre terras tradicionalmente ocupadas pelos índios também são direitos transindividuais, portanto, indisponíveis, de modo que o caso julgado no Recurso Extraordinário envolveu a violação de dois direitos transindividuais constitucionalmente protegidos.

Nesse sentido, defende-se que a imprescritibilidade da pretensão de reparação do dano ambiental pode também ser assentada em casos concretos erigidos em danos patrimoniais reflexos do dano ambiental provocado, danos que não necessariamente causam prejuízo aos povos indígenas.

E o presente trabalho buscou comprovar sua tese, a partir do método dedutivo, aplicando-se o método da hermenêutica teleológica e sistemática na interpretação do ordenamento jurídico brasileiro, bem como o marco teórico da Teoria Discursiva do Direito, estruturada por Robert Alexy (filósofo do direito não-positivista), que desenvolve um parâmetro hermenêutico de justiça e racionalidade para as decisões judiciais; e do método indutivo, a partir da análise de julgados do Superior Tribunal de Justiça, que já possui entendimento consolidado acerca da imprescritibilidade da pretensão de reparação do dano ambiental, e julgados do Supremo Tribunal Federal, cuja ratio decidendi favorece o mesmo 
entendimento.

\section{DA RELEVÂNCIA DO DIREITO AO MEIO AMBIENTE EQUILIBRADO E SAUDÁVEL}

O meio ambiente saudável e equilibrado é um direito transindividual de natureza difusa, de terceira geração - portanto, indisponível, irrenunciável e inalienável -, cuja violação afeta todo o planeta Terra, em última instância, tanto no aspecto da natureza - que é uma entidade que carece de proteção jurídica por si só, assim como todos os seres vivos que se encontram neste espaço geográfico -, quanto no aspecto dos seres humanos - que integram a coletividade dos seres vivos do planeta Terra, cuja sobrevivência depende do meio ambiente equilibrado e saudável, em caso contrário, podendo sofrer profundo impacto e prejuízo intergeracional, isto é, nas gerações atuais e futuras.

\subsection{Recurso Extraordinário n. 654833/AC, de 2020: marco na proteção ambiental brasileira}

A Constituição da República Federativo do Brasil de 1988 preza pela segurança jurídica, isto é, a previsibilidade das consequências para ações, omissões e eventos que independem da ação humana voluntária e consciente, a fim de promover, sobretudo, a paz nas relações interpessoais e a imparcialidade nos julgamentos dos eventos. Por essa razão, não há previsibilidade expressa acerca da possibilidade de imprescritibilidade de pretensões reparatórias relativas a danos sobre determinados bens, como é o caso de danos a direitos ecológicos, embora haja previsão de imprescritibilidade em relação aos crimes de racismo e à ação de grupos armados, civis ou militares, contra a ordem constitucional e o Estado Democrático, por exemplo (BRASIL, 1988).

Contudo, por meio de uma construção doutrinária e jurisprudencial, partindo de uma interpretação pautada nos princípios da justiça, na finalidade e sistemática do Direito, bem como na necessidade de humanização do Direito, é possível extrair a necessidade de imprescritibilidade da reparação de danos que recaem sobre determinados bens jurídicos, em razão de sua suma importância para o bem comum, como é o caso dos direitos ecológicos, que são direitos difusos. Ou, quando prevê a possibilidade de imprescritibilidade, não prevê os prazos adequados para tanto, como é o caso de ilícitos que causem prejuízo ao erário, com 
previsão no art. 37, §5º da Constituição da República (BRASIL, 1988).

Importante lembrar um exemplo emblemático pertinente à presente discussão, que é o da imprescritibilidade dos ressarcimentos ao erário, posição que sempre vigorou no Direito Administrativo até 2016, quando surgiu a discussão acerca da prática de ilícitos civis praticados por terceiros particulares.

O Supremo Tribunal Federal, então, no Recurso Extraordinário n. 669.069, em 2016, decidiu que se trata de ilícito civil, cometido por particular, o que não se enquadraria em hipótese de servidor nem ato de improbidade, de modo que, no caso de ilícitos civis, o ressarcimento ao erário seria prescritível, por dever prevalecer a segurança jurídica aos particulares, devendo-se aplicar aos casos o prazo prescricional de três anos previsto no Direito Civil. Ressalvou apenas a improbidade (BRASIL, 2016).

Essa posição criou uma lacuna no Direito Administrativo, até que, em 2018, a Suprema Corte mudou seu posicionamento, no Recurso Extraordinário n. 852.475, estabelecendo que o ressarcimento ao erário somente será imprescritível quando o ato de improbidade causar prejuízo ao erário de forma dolosa, a fim de desencorajar atos de corrupção e de violação da coisa pública, vista a sua relevância (BRASIL, 2018).

Em 2020, mais uma vez, a postura de priorizar o bem público e flexibilizar a segurança jurídica foi manifestada pelo Supremo Tribunal Federal, dessa vez em relação aos direitos ecológicos, em que foi reconhecida a imprescritibilidade da pretensão à reparação dos danos ambientais, em detrimento da segurança jurídica aos particulares. Nos termos do Recurso Extraordinário n. 654.833/AC, em sede de repercussão geral:

1.Debate-se nestes autos se deve prevalecer o princípio da segurança jurídica, que beneficia o autor do dano ambiental diante da inércia do Poder Público; ou se devem prevalecer os princípios constitucionais de proteção, preservação e reparação do meio ambiente, que beneficiam toda a coletividade.

2. Em nosso ordenamento jurídico, a regra é a prescrição da pretensão reparatória. A imprescritibilidade, por sua vez, é exceção. Depende, portanto, de fatores externos, que o ordenamento jurídico reputa inderrogáveis pelo tempo.

3. Embora a Constituição e as leis ordinárias não disponham acerca do prazo prescricional para a reparação de danos civis ambientais, sendo regra a estipulação de prazo para pretensão ressarcitória, a tutela constitucional a determinados valores impõe o reconhecimento de pretensões imprescritíveis.

4. O meio ambiente deve ser considerado patrimônio comum de toda humanidade, para a garantia de sua integral proteção, especialmente em relação às gerações futuras. Todas as condutas do Poder Público estatal devem ser direcionadas no sentido de integral proteção legislativa interna e de adesão aos pactos e tratados internacionais protetivos desse direito humano fundamental de $3^{\mathrm{a}}$ geração, para evitar prejuízo da coletividade em face de uma afetação de certo bem (recurso natural) a uma finalidade individual. 
5. A reparação do dano ao meio ambiente é direito fundamental indisponível, sendo imperativo o reconhecimento da imprescritibilidade no que toca à recomposição dos danos ambientais. (BRASIL, 2020, p. 1-2, grifo nosso).

Trata-se de um julgado marco na evolução de conquista de espaço pelos direitos ecológicos, tendo em vista que o Direito Ambiental é relativamente recente, em relação a grande parte dos ramos do Direito, pois começou a se desenvolver de maneira sistematizada a partir da década de 1970. Também se trata de conquista recente, no ordenamento jurídico brasileiro, em nível mais estruturado, a categoria de direitos transindividuais, originários de uma estrutura de Estado Democrático de Direito, que rompe com a priorização exclusiva dos direitos individuais, oriunda do modelo de Estado Liberal, e com a priorização exclusiva dos direitos sociais, oriunda do modelo de Estado do Bem-Estar Social.

E, uma vez reconhecido seu status de direito fundamental difuso, pertencente a uma titularidade indeterminada, é de suma importância que seja priorizada preservação ambiental, mesmo em detrimento de direitos individuais, pois o meio ambiente equilibrado é um direito que pertence a todos os indivíduos conjuntamente, e uma lesão causada por uma única pessoa pode repercutir na esfera de direitos de toda a coletividade.

\subsection{Jurisprudência do Superior Tribunal de Justiça acerca da imprescritibilidade da pretensão de reparação do dano ambiental}

Importante ressaltar que a doutrina já reconhecia a imprescritibilidade de pretensão de reparação do dano ambiental, conforme ensinamento de Mazzili (2006, p. 540-541), no sentido de que, quando se tratam de direitos transindividuais, não podem evocar regras de prescrição próprias do Direito Civil, e, por se tratar de direito transindividual, indisponível e coletivo, é imprescritível, pertencente a todas as gerações, "não se podendo formar direito adquirido de poluir". "Pois uma geração não pode impor às seguintes o eterno ônus de suportar a prática de comportamentos que podem destruir o próprio habitat do ser”.

O Supremo Tribunal Federal havia não havia se manifestado acerca da matéria, até a prolação do julgado emblemático analisado. Por sua vez, o Superior Tribunal de Justiça já vinha reconhecendo a imprescritibilidade da pretensão de reparação por danos ambientais, por se tratar de direito fundamental indisponível, inerente à própria manutenção da vida, nos termos do Recurso Especial n. 1.120.117/AC, de relatoria da ministra Eliana Calmon: 
ADMINISTRATIVO E PROCESSO CIVIL - DIREITO AMBIENTAL - AÇÃO CIVIL PÚBLICA? COMPETÊNCIA DA JUSTIÇA FEDERAL? IMPRESCRITIBILIDADE DA REPARAÇÃO DO DANO AMBIENTAL? PEDIDO GENÉRICO? ARBITRAMENTO DO QUANTUM DEBEATUR NA SENTENÇA: REVISÃO, POSSIBILIDADE - SÚMULAS 284/STF E 7/STJ.

$[\ldots]$

4. O dano ambiental além de atingir de imediato o bem jurídico que lhe está próximo, a comunidade indígena, também atinge a todos os integrantes do Estado, espraiando-se para toda a comunidade local, não indígena e para futuras gerações pela irreversibilidade do mal ocasionado.

5. Tratando-se de direito difuso, a reparação civil assume grande amplitude, com profundas implicações na espécie de responsabilidade do degradador que é objetiva, fundada no simples risco ou no simples fato da atividade danosa, independentemente da culpa do agente causador do dano.

6. O direito ao pedido de reparação de danos ambientais, dentro da logicidade hermenêutica, está protegido pelo manto da imprescritibilidade, por se tratar de direito inerente à vida, fundamental e essencial à afirmação dos povos, independentemente de não estar expresso em texto legal.

7. Em matéria de prescrição cumpre distinguir qual o bem jurídico tutelado: se eminentemente privado seguem-se os prazos normais das ações indenizatórias; se o bem jurídico é indisponível, fundamental, antecedendo a todos os demais direitos, pois sem ele não há vida, nem saúde, nem trabalho, nem lazer, considera-se imprescritível o direito à reparação.

8. O dano ambiental inclui-se dentre os direitos indisponíveis e como tal está dentre os poucos acobertados pelo manto da imprescritibilidade a ação que visa reparar o dano ambiental.

[...] (BRASIL, 2009, p. 1-2, grifo nosso).

Porém, em relação aos danos reflexos patrimoniais, o referido tribunal defendia uma posição de prescritibilidade, porque, embora reconhecesse que o dano ambiental pode não ser direcionado apenas a uma coletividade, mas afetar particulares de maneira específica, causando-lhe danos pessoais (o chamado dano ambiental individual ou dano por intermédio do meio ambiente), isto é, danos reflexos.

Outro precedente da Corte Superior que reforça exatamente o mesmo entendimento é o Recurso Especial n. 1.346.489/RS (BRASIL, 2013), de relatoria do ministro Ricardo Villas Bôas Cueva, que afirma que os danos reflexos ambientais são normatizados pela legislação civil, submetendo-se à prescrição, porque afetam pessoa e bem específicos, ou seja, uma titularidade definida. Contudo, ressalta que a matéria gera incertezas jurídicas, apesar do entendimento que vem dominando.

\section{A HERMENÊUTICA COMO BASE DE SUSTENTAÇÃO DA IMPRESCRITIBILIDADE DA PRETENSÃO DE REPARAÇÃO POR DANO AMBIENTAL}

O objetivo do presente capítulo é demonstrar como a tese da imprescritibilidade da 
pretensão de reparação por dano ambiental pode ser solidamente sustentada pela hermenêutica teleológico-sistemática e pela teoria discursiva do Direito de Robert Alexy, mormente pela técnica da ponderação, e são essas teorias da interpretação e argumentação que embasarão a possibilidade de imprescritibilidade dos danos patrimoniais reflexos dos danos ambientais.

\subsection{Da hermenêutica teleológico-sistemática}

Por que a hermenêutica teleológico-sistemática? Porque possui relação direta com o marco teórico da tese aqui defendida, que é a teoria discursiva do Direito de Robert Alexy. Na visão deste autor, funciona como algumas das diretrizes básicas.

A interpretação sistemática parte do pressuposto de que o sistema jurídico do ordenamento funciona como uma unidade, com base em uma hierarquia das fontes normativas, cujo topo se encontra na Constituição, e todo preceito deve ser interpretado em harmonia com os princípios gerais que regem o sistema, conferindo coerência ao ordenamento. Daí a ideia de revogação tácita de uma norma, que ocorre quando um preceito se torna incompatível ou é substituição de maneira global por uma nova regulamentação acerca da matéria (FERRAZ JÚNIOR, 2008).

Com base nesse método de interpretação, é possível claramente a imprescritibilidade da pretensão de reparação por dano ambiental. Ora, se o sistema jurídico funciona como uma unidade que deve ser interpretado com base nos princípios gerais regentes, pode-se dizer que o principal princípio regente dos direitos fundamentais é o princípio da dignidade da pessoa humana, do qual se extraem todos os demais que, consequentemente, devem atender ao seu comando.

Não há falar, em resumo, ao direito à vida e à saúde e, portanto, à dignidade do ser humano, sem a existência de um meio ambiente ecologicamente equilibrado, porque do meio ambiente se extraem todas as condições para uma vida saudável: alimentação, moradia, higiene, trabalho, cultura, interação humana, itens sem os quais o ser humano não sobrevive. É no meio ambiente, que o ser humano vive e convive.

Nesse sentido, o dano ambiental, considerado, o meio ambiente, um direito difuso, afeta toda uma coletividade indeterminada de pessoas, de modo que sua proteção deve prevalecer inclusive sobre direitos individuais patrimoniais, em detrimento da segurança jurídica do autor do dano, porque se abre mão dos direitos patrimoniais de uma única pessoa, 
sem os quais ela possivelmente continuará vivendo. Trata-se de analisar o ordenamento jurídico como um todo e verificar quais são as normas regentes dos princípios gerais, priorizando a proteção de bem público, não simplesmente por ser um bem público e não individual, mas por abranger condições indispensáveis até mesmo à vida do coletivo.

A interpretação teleológica, por sua vez, parte do pressuposto de que "sempre é possível atribuir um propósito às normas" (FERRAZ JÚNIOR, 2008, p. 265), até mesmo com a finalidade de atenuar a carga emocional que se encontra depositada nos símbolos, significantes. As normas sempre buscam alcançar os fins sociais do direito e as exigências do bem comum, como previsto na Lei de Introdução às Normas de Direito Brasileiro, até mesmo como uma forma de prever as consequências dos conflitos para tomar a decisão mais coerente (FERRAZ JÚNIOR, 2008).

Em uma interpretação teleológica acerca da proteção do meio ambiente no ordenamento jurídico brasileiro, pode-se notar que, uma vez considerados como direitos transindividuais, são direitos fundamentais pertencentes a toda a coletividade, enquadrando-se na categoria de direitos de terceira dimensão, envolvendo as ideias de solidariedade e fraternidade. Uma vez que o meio ambiente está em todas as partes, o Estado não dispõe sozinho de condições para fiscalização e impedimento da provocação de danos dessa natureza.

Por essa razão, é preciso que o ser humano se una, cada um desempenhando sua parte, para a preservação ambiental no dia a dia, a partir de cada conduta empreendida. A finalidade das normas de proteção ambiental é também justamente trazer essa noção de contribuição com o coletivo por parte do indivíduo. Por essa razão, uma vez que os direitos ambientais são direitos fundamentais transindividuais de suma relevância, já definido pela Constituição, estabelecer a imprescritibilidade da pretensão de reparação dos danos sofridos constitui uma forma de inibir os indivíduos a empreenderem qualquer conduta que ponha em xeque sua proteção, pois um mero deslize de cada indivíduo promove, em conjunto, uma degradação ambiental irreversível e irreparável em termos de recomposição.

E, ainda assim, como bem ressaltado por Freitas e Pompeu (2019), o Direito Ambiental foi criado por um Estado Industrial e Tecnológico, de maneira que não consegue cumprir com sua função originária de administrar e prevenir riscos, apresentando um verdadeiro retrocesso ecológico, ilustrado pelas edições do Novo Código Florestal Brasileiro, da nova Lei de Licenciamento Ambiental e da Emenda Constitucional da Vaquejada, 
funcionando, na realidade, como um Direito simbólico.

\subsection{Teoria Discursiva do Direito de Robert Alexy}

Robert Alexy apresenta uma concepção não-positivista do Direito, segundo a qual, e que traz uma distinção semântica qualitativa entre regras e princípios (ALEXY, 2012, p. 5152), focando nas normas com conteúdo de direito fundamental e mostrando-se uma teoria mais analítica, precisa e normativa (TOVAR, 2015, p. 173), que permite que os direitos fundamentais sejam efetivados na maior medida possibilitada pelo caso concreto em análise.

Segundo Alexy (2012, p. 53), as normas de direitos fundamentais apresentam conteúdo deôntico, ou seja, de dever-ser, e os direitos fundamentais são normas que delineiam a estrutura fundamental da sociedade e possui o grau mais elevado de regulação, por estarem dispostos na legislação de maior hierarquia, que é a Constituição, razão pela qual sua interpretação permite uma maior flexibilização no momento da aplicação no caso concreto, a fim de serem preservados e não se apresentarem na configuração de aplicação de tudo-ounada.

Daí a distinção fundamental entre regras e princípios, uma vez que ambos são normas com conteúdo deôntico, mas os princípios são aplicados em graus, em cada caso concreto, conforme suas possibilidades fáticas e jurídicas, de modo que os direitos fundamentais se apresentam, por clara inferência, com natureza jurídica de princípio (ALEXY, 2015, p. 190).

Os princípios, portanto, são comandos de otimização, que serão aplicados em maior ou menor medida ao caso, quando em colisão com outros princípios. As possibilidades jurídicas são compostas por outras regras e princípios aplicáveis ao caso. A prevalência de um ou outro princípio no caso concreto dependerá do peso concreto que cada um apresentará, após equacionado um conjunto de premissas na fórmula do peso, mas não prevalência de um princípio não o exclui do ordenamento jurídico, ele será sempre válido (ALEXY, 2012, p. 93 94).

Não há princípio absoluto, que sempre prevaleça em todo caso concreto, tudo depende de uma ponderação a ser realizada por meio da fórmula do peso. Em um caso concreto, sempre será construída uma relação de precedência de um princípio em face de outro, com base nas possibilidades fáticas e jurídicas que permeiam o caso, é a chamada lei da colisão (ALEXY, 2012, p. 98-99). 
As possibilidades são compostas pela máxima da proporcionalidade e suas três vertentes: adequação (aptidão do meio ao alcance do fim pretendido), necessidade (escolha do meio adequado menos gravoso) e proporcionalidade em sentido estrito (ALEXY, 2014, p. 5354), que é a verdadeira ponderação - cumprida a partir das seguintes fases: determinar o grau em que um princípio x é descumprido; determinar o grau em que o princípio y contraposto deve ser cumprido; concluir se justifica descumprir o princípio y para cumprir o x (ALEXY, 2005, p. 574).

A ponderação é composta por duas leis. A primeira determina que o grau de cumprimento de um princípio deve ser inversamente proporcional ao grau de descumprimento do contraposto (ALEXY, 2005, p. 573). A segunda determina que o descumprimento de um princípio de direito constitucional deve ser diretamente proporcional ao grau de certeza ou confiabilidade nas premissas subjacentes a ele (ALEXY, 2007, p. 25).

A fórmula do peso é um sistema inferencial lógico, cujas premissas são estabelecidas implicitamente e representadas por uma escala triádica numérica, que representam as intensidades e graus de certeza, a fim de facilitar a compreensão o caminho a ser seguido para a conclusão acerca do resultado da ponderação. Todas as premissas, com seus respectivos valores atribuídos, devem ser passíveis de justificação (argumentação racional), para que o raciocínio seja racional e válido (ALEXY, 2005, p. 576). Na versão mais atual de sua teoria, Alexy apresentou a fórmula do peso refinada (ALEXY, 2014, p. 513-514), assim representada:

$$
W_{i, j}=\frac{I_{i} \times W_{i} \times R_{j}^{e} \times R_{i}^{n}}{I_{j} \times W_{j} \times R_{j}^{e} \times R_{j}^{n}}
$$

Sendo que $W i, j$ é o peso do princípio $P i$ em relação ao princípio oposto $P j$; $I i$ é o grau de descumprimento do $P i$; $I j$ é a importância de se cumprir $P j$; Wi e $W j$ representam os pesos abstratos dos princípios em análise e geralmente são iguais, neutralizando, por se tratarem, ambos, de direitos constitucionais (de mesmo peso); $R i$ e $R j$ são o grau de certeza nas premissas empíricas e normativas referentes ao nível de descumprimento de $P i$ e de descumprimento de $P j$, se $P i$ não fosse descumprido (ALEXY, 2014, p. 513-514).

As variáveis do peso abstrato e do descumprimento são classificadas, na escala 
triádica, como leve, moderada ou grave, valoradas pela escala geométrica como $2^{\circ}$ (igual a 1), $2^{1}$ (igual a 2) e $2^{2}$ (igual a 4), enquanto as premissas de certeza ou confiabilidade são classificadas como confiável, plausível e não evidentemente falso, valoradas pela escala geométrica como $2^{\circ}$ (igual a 1), $2^{-1}$ (igual a 1/2) e $2^{-2}$ (igual a 1/4) (ALEXY, 2014, p. 515).

No caso específico de haver uma colisão de direitos fundamentais em concreto entre o direito à segurança jurídica do indivíduo que pratica um dano ambiental e o direito ao meio ambiente ecologicamente equilibrado, deve-se verificar, a partir da técnica da ponderação de Alexy, pela fórmula do peso, qual direito prevalece, isto é, possui mais peso no caso. E, para que a seja endossada a imprescritibilidade da pretensão à reparação do dano ambiental, é preciso que o direito ao meio ambiente ecologicamente equilibrado prevaleça, pois a imprescritibilidade é uma preterição à segurança jurídica do indivíduo autor do dano.

Suponha que $i$ represente o princípio do direito ao meio ambiente ecologicamente equilibrado, e $s$ represente o princípio da segurança jurídica do indivíduo autor do dano ambiental.

O direito ao meio ambiente ecologicamente equilibrado está previsto na Constituição da República (art. 225), inclusive, com direito à proteção pelo Ministério Público, enquanto seu dever institucional de defesa dos direitos transindividuais e de vulneráveis, que são mais caros ao Estado Democrático de Direito (art. 129) (BRASIL, 1988).

Também está previsto no ordenamento internacional, por meio de documentos como a Declaração Universal dos Direitos Humanos (1948), a Declaração de Estocolmo sobre o Meio Ambiente Humano (1972), a Carta Mundial da Natureza (1982), a Carta da Terra (2000) e vários outros documentos oriundos de conferências e protocolos, que contribuíram para o “desenvolvimento da concepção do socioambientalismo, prevendo a implementação de formulações políticas, sociais e ambientais em todo o mundo" (KALIL; FERREIRA, 2017, p. 332).

Por fim, está previsto na legislação infraconstitucional com uma ampla gama de princípios norteadores, como princípio do poluidor-pagador, princípio da precaução, princípio da prevenção, princípio da progressividade e princípio in dubio pro natura, bem como possui previsão na jurisprudência sólida do Supremo Tribunal Federal. Ou seja, pode-se lhe atribuir, inicialmente, peso abstrato (Wi) máximo, 4.

Do mesmo modo, pode-se atribuir peso (Ws) máximo, 4, ao princípio da segurança jurídica, sem maior necessidade argumentativa, por razões já solidificadas na doutrina jurídica 
acerca da imprescindibilidade do princípio para a manutenção do Estado Democrático de Direito.

Quando ao grau de descumprimento e cumprimento de cada princípio, pode-se dizer que o grau de descumprimento do princípio do direito ao meio ambiente ecologicamente equilibrado deve ser grave ( $\mathrm{Ii}=4)$, pois deve possuir o mesmo grau de importância do cumprimento do princípio da segurança jurídica (Is $=4)$.

Até então, verifica-se que a equação encontra um impasse, as premissas estão se anulando. Contudo, ao se verificarem as premissas normativas e empíricas subjacentes a cada princípio, verifica-se que não há confiabilidade nas premissas que permitiriam uma violação da segurança jurídica registral em prol do direito ao meio ambiente ecologicamente equilibrado.

O direito ao meio ambiente ecologicamente equilibrado é um princípio substantivo (seu conteúdo é um direito que representa um bem da vida), enquanto a segurança jurídica é um princípio formal, que diz respeito à dimensão de realidade conceitual do direito, exigindo otimização da legalidade e da eficácia social (ALEXY, 2014, p. 516).

O princípio formal determina que as regras elaboradas pelas autoridades estatais legitimadas impõem seu próprio cumprimento, de maneira que não podem ser relativizadas ou flexibilizadas sem motivos fortes estabelecidos (ALEXY, 2014, p. 516-517), salvo se estiver diante de uma injustiça extrema, que faz com que o direito deixe de ser direito, razão pela qual, deve-se afastar a segurança jurídica e, portanto, a aplicação da lei formal, caso em que o direito cederia à correção moral (TRIVISONNO, 2015, p. 111).

Em relação às premissas empíricas e normativas, correspondem à possibilidade de interferência (descumprimento) no referido direito pelo direito oposto em ponderação, de modo que, por exemplo, as premissas relativas ao princípio i, do direito ao meio ambiente ecologicamente equilibrado, devem ser valoradas com base na possibilidade desse direito ser descumprido pelo direito à segurança jurídica. E a possibilidade de descumprimento do princípio da segurança jurídica (a valoração de suas premissas) deve ser valorada com base nas consequências que disso poderiam advir.

As premissas empíricas correspondem à certeza quanto às reais consequências de se assegurar o cumprimento de cada direito equivalente. A seu turno, as premissas normativas correspondem ao respaldo normativo para se cumprir cada princípio equivalente, em detrimento do princípio oposto. Em relação a danos a bens difusos, como meio ambiente, 
deve-se considerar que:

O dano pode ser insignificante, se avaliado somente do ponto de vista do caso concreto isoladamente. Porém, se somados os resultados de várias ínfimas lesões, tem-se uma grande ofensa, talvez irreparável, razão pela qual a importância do cumprimento desses bens jurídicos deve tender a ser maior do que a direitos individuais de indivíduos tomados isoladamente. (SANTOS, 2018, p. 180).

Portanto, comparando-se o respaldo normativo para o cumprimento, bem como as consequências que podem advir do descumprimento de cada princípio envolvido na presente ponderação, considerando a necessidade de inibir que certas condutas sejam praticadas contra o meio ambiente, justamente por ser um bem coletivo de fácil ofensa, cujos danos são, em grande parte, de difícil reparação e reversibilidade, resta claro que o valor final da fórmula peso indica para a precedência do princípio do direito ao meio ambiente ecologicamente equilibrado, o qual deve prevalecer, razão pela qual, justifica-se juridicamente a determinação da imprescritibilidade da pretensão de reparação dos danos ambientais.

\section{DA IMPRESCRITIBILIDADE DA PRETENSÃO DE REPARAÇÃO DOS DANOS PATRIMONIAIS REFLEXOS DO DANO AMBIENTAL}

Em relação ao conceito de dano reflexo, é difícil "encontrar conceitos operacionais claros [...] que consigam identificar os danos reflexos como categorias jurídicas autônomas e dotadas de um conteúdo eficacional próprio" (SILVA; SANTOS, 2013, p. 96-97). Essa categoria de danos não possui previsão legal expressa, sendo fruto de construção doutrinária e jurisprudencial, inclusive, na doutrina internacional. Mas o que se pode pontuar é que "o dano reflexo ou por ricochete trata-se de dano próprio do terceiro, haja vista ter um objeto distinto daquele inicialmente causado", podendo se caracterizar pela natureza patrimonial ou extrapatrimonial, inclusive, com quantum indenizatório autônomo (SILVA; SANTOS, 2013, p. 105).

Claramente, os danos reflexos são institutos do direito civil, sejam os de natureza patrimonial ou extrapatrimonial, pois não são danos aos direitos ambientais propriamente, mas danos promovidos na esfera pessoal individual, em decorrência do dano ambiental promovido. Entretanto, por toda a hermenêutica até aqui empregada, resta claro que é possível, tanto por uma interpretação teleológico-sistemática, quanto pela teoria discursiva do Direito de Alexy, estender a imprescritibilidade da pretensão de reparação aos danos 
patrimoniais reflexos, por algumas justificativas.

Se a finalidade do ordenamento jurídico é justamente resguardar prioritariamente bens públicos de maior vulnerabilidade, que afetam toda uma coletividade, como o meio ambiente, cujo estado equilibrado é inerente à qualidade de vida e de saúde da população, bem como cujos danos sofridos, muitas vezes, são irreversíveis e irreparáveis, é plenamente possível estender a mesma proteção à extensão desses danos sofridos, que, no caso, são os danos reflexos.

Justamente por se tratar de um direito de cuja qualidade de vida e saúde da coletividade depende diretamente, é óbvio que os danos sofridos por esse bem jurídico acabarão repercutindo de tamanha forma, que atingirá inclusive esferas particulares. E porque fazer essa diferenciação em termos de prescritibilidade, se a origem do dano é a mesma? Trata-se até mesmo de uma situação de violação da igualdade substancial de tratamento das vítimas - quando for a coletividade e quando for o indivíduo.

E a mesma dificuldade que o Estado pode ter para identificar e efetivamente tomar providências para reparação do dano, o particular também pode ter, porque um dano ambiental já não é de fácil constatação para um particular, pois para que ele seja constatado por alguém que não um órgão fiscalizador, sobretudo, quando não deixar rastros claramente perceptíveis, pode levar muito tempo, ao ponto de o fato se submeter efetivamente ao prazo prescricional do Direito Civil, que é relativamente curto nessas circunstâncias.

Se, no caso concreto, não houver sido causado um dano concreto ao meio ambiente pela conduta do autor, mas tão somente uma exposição a dano, de fato, não haveria que se fazer uma relação entre os danos sofridos na esfera particular, porque não se poderia considerar que os danos reflexos se originaram de um dano ambiental. Mas a partir do momento em que houve o dano ambiental, e os danos são comprovadamente reflexos, tratamse de uma mera extensão de um dano a direito difuso, cuja pretensão reparatória é imprescritível.

E conferir referido tratamento de imprescritibilidade à pretensão reparatória dos danos reflexos, inclusive, reforça a função pedagógica da imprescritibilidade da pretensão reparatória do dano ambiental, que é inibir a prática de condutas que violem a condição sadia do meio ambiente, pois uma vez que os danos ambientais, via de regra, apresentam quase inevitável repercussão para esferas particulares, o particular terá muito mais cautela ao empreender ações que coloquem em risco a preservação ambiental, uma vez que estará 
enfrentando uma possibilidade a mais de ser juridicamente cobrado por prazo indeterminado.

Tomando por base, ainda, a teoria discursiva do Direito de Alexy, cuja imprescritibilidade da pretensão de reparação do dano ambiental foi aqui diretamente ligada à precedência do direito correspondente (meio ambiente ecologicamente equilibrado), analogamente, permitir que a segurança jurídica do particular autor do dano sobressaia à imprescritibilidade de pretensão de reparação do dano reflexo é afirmar que o direito à segurança jurídica do particular autor do dano tem prevalência sobre o direito do particular afetado por ricochete pelo dano ambiental provocado, o que correspondente a uma injustiça, nos moldes em que foi trazida a técnica da ponderação de Alexy, além de corresponder a uma desproporcionalidade.

\section{CONCLUSÃO}

O presente trabalho, então, buscou analisar se de fato seria possível defender a imprescritibilidade da pretensão de reparação de dano reflexo ao dano ambiental, com base nos métodos hermenêuticos teleológico-sistemático e na teoria discursiva do Direito de Robert Alexy, de maneira análoga à imprescritibilidade da pretensão de reparação de ambiental reconhecida pelo Supremo Tribunal Federal em sede de repercussão geral.

Restou, então, endossada a possibilidade, tanto em razão de uma função pedagógica da reparação de danos, quanto para manter a igualdade substancial de tratamento entre as vítimas de danos, bem como manter uma coerência na priorização do direito difuso ao meio ambiente, considerando que o dano reflexo patrimonial é uma extensão direta do dano ambiental, com origem comum.

Considerando a sistemática e finalidade do ordenamento jurídico protetivo do meio ambiente, bem como a técnica da ponderação proposta por Alexy, não há coerência jurídica (interpretativa e argumentativa) em desvincular o dano ambiental do dano patrimonial em ricochete. Até mesmo porque, se aplicarem-se os princípios do Direito Civil, por se tratar de direito eminentemente civil, dever-se-ia seguir a regra básica de tratamento de que o acessório segue o principal, então, uma vez que os danos reflexos possuem origem nos danos ambientais, inexistindo na ausência dos mesmos, não há porque desvincular o tratamento jurídico prescricional dado a ambos, pois não há origem autônoma nos danos reflexos. 


\section{REFERÊNCIAS}

ALEXY, Robert. Balancing, constitutional review, and representation. I•CON: Oxford University Press and New York University School of Law, v. 3, n. 4, pp. 572-581, 2005. Disponível em: https://academic.oup.com/icon/article/3/4/572/792008. Acesso em: 18 nov. 2020.

ALEXY, Robert. Constitutional Rights and Proportionality. Revus - Journal for Constitutional Theory and Philosophy of Law, v. 22, p. 51-65, 2014. Disponível em: https://journals.openedition.org/revus/pdf/2783. Acesso em: 18 nov. 2020.

ALEXY, Robert. Formal principles: some replies to critics. Oxford University Press and New York University School of Law, v. 12, n. 3, p. 513-524, 2014. Disponível em: https://academic.oup.com/icon/article/12/3/511/763784. Acesso em: 18 nov. 2020.

ALEXY, Robert. Teoria discursiva do Direito. Organização, tradução e estudo introdutório de Alexandre Travessoni Gomes Trivisonno. 2. ed. Rio de Janeiro: Forense Universitária, 2015.

ALEXY, Robert. Teoria dos direitos fundamentais. Tradução de Virgílio Afonso da Silva. São Paulo: Malheiros Editores, 2012.

ALEXY, Robert. The weight formula. In: STELMACH, Jerzy; BROŻEK, Bartosz; ZAŁUSK, Wojciech. Studies in the Philosophy of Law: Frontiers of the economic analysis of law. Kraków: Jagiellonian University Press, 2007. P. 9-27.

BRASIL. Constituição [(1988)]. Constituição da República Federativa do Brasil de 1988. Brasília, DF: Presidência da República, [1988]. Disponível em: http://www.planalto.gov.br/ccivil_03/constituicao/constituicao.htm. Acesso em: 20 maio 2021.

BRASIL. Superior Tribunal de Justiça. Recurso Especial n. 1.120.117/AC. Relatora: Min. Eliana Calmon, 10 nov. 2009. Brasília, DF: STJ, 2009. Disponível em: https://scon.stj.jus.br/SCON/GetInteiroTeorDoAcordao?num_registro=200900740337\&dt_pu blicacao=19/11/2009. Acesso em: 29 maio 2021.

BRASIL. Superior Tribunal de Justiça. Recurso Especial n. 1.346.489/RS. Relatoria: Min. Ricardo Villas Bôas Cueva, 11 jun. 2013. Brasília, DF: STJ, 2013. Disponível em: Acesso em: 20 maio 2021.

BRASIL. Supremo Tribunal Federal (Pleno). Recurso Extraordinário n. 654833/AC. Recurso extraordinário. Repercussão geral. Tema 999. Constitucional. Dano ambiental. Reparação. Imprescritibilidade. Relator: Min. Alexandre de Moraes, 20 abr. 2020. Brasília: STF, 2020. Disponível em: http://portal.stf.jus.br/processos/downloadPeca.asp?id=15343546770\&ext=.pdf. Acesso em: 26 mar. 2021.

BRASIL. Supremo Tribunal Federal (Pleno). Recurso Extraordinário n. 669069/MG. 
Repercussão geral. Tema 666. Constitucional e civil. Ressarcimento ao erário. Imprescritibilidade. Sentido e alcance do art. 37, § 5 , da Constituição. Relator: Min. Teori Zavascki, 03 fev. 2016. Brasília: STF, 2016. Disponível em:

https://portal.stf.jus.br/processos/downloadPeca.asp?id=309316367\&ext=.pdf. Acesso em: 26 mar. 2020.

BRASIL. Supremo Tribunal Federal (Pleno). Recurso Extraordinário n. 852475/SP. Repercussão geral. Tema 897. Direito constitucional. Direito administrativo. Ressarcimento ao erário. Imprescritibilidade. Sentido e alcance do art. 37, § 5 , da Constituição. Relator: Min. Alexandre de Moraes, 08 ago. 2018. Brasília: STF, 2019. Disponível em: https://portal.stf.jus.br/processos/downloadPeca.asp?id=15339769948\&ext=.pdf. Acesso em: 26 mar. 2020.

FERRAZ JÚNIOR, Tércio Sampaio. Introdução ao estudo do direito: técnica, decisão, dominação. 6. ed. São Paulo: Atlas, 2008.

FREITAS, Ana Carla Pinheiro; POMPEU, Gina Vidal. A função simbólica do direito ambiental: considerações sobre o tema 30 anos depois da Constituição de 1988. Veredas do Direito, Belo Horizonte, v. 16, n. 34, p. 235-252, jan./abr. 2019. Disponível em: http://revista.domhelder.edu.br/index.php/veredas/article/view/1328. Acesso em: 28 maio 2021.

KALIL, Ana Paula Maciel Costa; FERREIRA, Heline Sivini. Veredas do Direito, Belo Horizonte, v. 14, n. 28, p. 329-359, jan./abr. 2017. Disponível em: http://revista.domhelder.edu.br/index.php/veredas/article/view/1010. Acesso em: 29 maio 2021.

MAZZILI, Hugo Nigro. A defesa dos direitos difusos em juízo. 19. ed., rev., ampl. e atual. São Paulo: Saraiva, 2006.

SANTOS, Najara Cristiane dos. Banalização dos princípios jurídicos: a deturpação pelo direito penal. 2018. 215 f. Dissertação (Mestrado em Direito) - Programa de Pós-Graduação em Direito, Pontifícia Universidade Católica de Minas Gerais, Belo Horizonte, 2018. Disponível em: http://www.biblioteca.pucminas.br/teses/Direito_SantosNC_1.pdf. Acesso em: 24 abr. 2021.

SILVA, Rafael Peteffi da; SANTOS, Aline Ávila Ferreira dos. Indenização do dano reflexo extrapatrimonial: situação do Direito brasileiro em perspectiva comparativa. Prisma Jur., São Paulo, v. 12, n. 1, p. 95-129, jan./jun. 2013. Disponível em: https://periodicos.uninove.br/prisma/article/view/4317/2528. Acesso em: 30 maio 2021.

SOUZA, Paulo Roberto Pereira de. Os princípios do Direito Ambiental como instrumentos de efetivação da sustentabilidade do desenvolvimento econômico. Veredas do Direito, Belo Horizonte, v.13, n. 26, p.289-317, maio/ago. 2016. Disponível em: http://revista.domhelder.edu.br/index.php/veredas/article/view/705. Acesso em: 28 maio 2021.

TOVAR, Alejandro Nava. La institucionalización de la razón: la filosofía del derecho de 
Robert Alexy. Prefácio de Martin Borowski. Barcelona: Anthropos Editorial; México: Universidad Autónoma Metropolitana - Iztapalapa, 2015. (Autores, Textos y Temas. Filosofía; 88). 